\title{
Value Addition to Waste Material Supported by Removal of Available Phosphate from Simulated Brackish Water-A Low Cost Approach
}

\author{
S. Malavipathirana ${ }^{1 *}$, S. Wimalasiri ${ }^{2}$, N. Priyantha ${ }^{1 \dagger}$, S. Wickramasooriya ${ }^{1}$, \\ A. Welagedara ${ }^{3}$, G. Renman ${ }^{3}$ \\ ${ }^{1}$ Postgraduate Institute of Science, University of Peradeniya, Peradeniya, Sri Lanka \\ ${ }^{2}$ Department of Food Science and Technology, University of Perradeniya, Peradeniya, Sri Lanka \\ ${ }^{3}$ Department of Land and Water Resources Engineering, Royal Institute of Technology, Stockholm, Sweden \\ Email: "malavisarath@gmail.com, namalpriyantha@pdn.ac.lk
}

Received August 2013

\begin{abstract}
Phosphorus is one of the major nutrients that have been identified as a limited resource that would end up earlier than predicted at the rate of current consumption. Therefore, attempts to recover phosphorus from waste and its subsequent use are a concern of current researchers. Nevertheless, recovery of nutrients from wastewater is cumbersome because nutrients such as phosphates $\left(\mathrm{PO}_{4}^{3-}\right)$ and nitrates $\left(\mathrm{NO}_{3}^{-}\right)$prefer to remain in aqueous phase rather than being adsorbed on solid matrixes. Investigation of adsorption of available $\mathrm{PO}_{4}^{3-}$ - $\mathrm{P}$ from simulated brackish water, on granulated solid waste material, prepared by crushed autoclaved aerated concrete (CAAC), and subsequent use of the material as phosphate fertilizer would be the focus of this research. Treatment of nutrient-rich brackish water is important because such water is discharged in huge volume at the time of harvesting of shrimp aquaculture ponds. Experiments conducted in simulated brackish water confirmed non-linear adsorption association with changing distribution coefficient $\left(K_{D}\right)$ which attributed the maximum removal of about $98 \% \mathrm{PO}_{4}^{3-}-\mathrm{P}$ from 100 $\mathrm{mg} \cdot \mathrm{dm}^{-3}$ solution at its value of 40 . The non-linear adsorption supported by both the Langumuir and the Freundlich isotherm models simultaneously satisfied monolayer adsorption and multilayer adsorption depicted by the regression coefficients of greater than .99 by the linearized forms of the isotherm models. Moreover, promising phosphate uptakes characteristics are exhibited by the adsorbent at the process of repetitive adsorption which resulted in $12 \mathrm{~g} / \mathrm{kg}$ uptake of phosphate at $81 \%$ efficiency. The adsorbent seems to be used as a slow-released phosphorus fertilizer at the end of its life as an adsorbent.
\end{abstract}

Keywords: Aquaculture; Adsorption; Distribution Coefficient; Nutrient Loading; Phosphate Fertilizer; Pollution; Potentially Toxic Elements

\section{Introduction}

Phosphate is an essential and major nutrient that promotes the growth of all types of flora. Use of phosphate fertilizer is therefore common in practice in agriculture. Nevertheless, application of fertilizers in excess with the belief of obtaining higher yield is a common trend in many agricultural based countries. In addition to agricultural based run off, nutrients are rich in domestic wastewater (Kuzawa, Jung, Kiso, Yamada, Nagai, \& Lee, 2006). Population growth causes nutrient loading in the environment, irrespective of the route sources of such nutrients. Consequently, nutrient found in excess or presence of nutrients at inappropriate locations is considered as nutrient pollution (Malavipathirana, Wimalasiri, Priyantha, Wickramasooriya, Welagedara, \& Renman, (submitted)). Causes of pollution can either be due to geogenic characteristics of the specific area, or it may be a reason of anthropogenic inputs which diversified along with human activities.

Nutrient pollution has been received immense attention as it

\footnotetext{
"Corresponding author.

${ }^{\dagger}$ This author was assigned to facilitate domestic funding requirements.
}

can impair the quality of the receiving environment while decline and/or stop the quantity of output from the receiving environment. In other words, it may result in complete loss of sustainability of the recipient. The recipient, most of time, would be a water body such as a river, stream, and even brackish water environment. This is because, nearly infinite solubility of many nutrients in aqueous phase enabling them to easy mobilization with water. Some attempts made to prevent entering of nutrients into water ways, have emerged undesirable consequences. For instance, contamination of milk powder with dicyandiamide (DCD) used in pasture to manage nitrate formation and subsequent leaching into water bodies (Editorial, 2013).

In the context of marine environment and associated activities such as aquaculture, harbor activities, attribute heavy pollution loads which leads to eutrophication, silting, oxygen depletion and contribution of heavy metals, residues of pesticides and antibiotics, disinfectant by-products and many other organic and inorganic pollutants broadly defined as potentially toxic elements (PTEs) (Le \& Munekage, 2004; Marhaba, Mangmeechai, Chaiwatpongsakom, \& Payasant, 2006; Colt, 2006; Sapkota(a), Sapkota(b), Kucharski, Burke, McKenzie, Walker, \& Law- 
rence, 2008; Wu \& Yang, 2010; Paul \& Vogal, 2011; Malavipathirana, Mubarak, \& Perera, 2013).

The costal belt of the many Asian countries is inherent with saltwater (brackish) lagoon, estuaries, mangrove and costal mud flats which are potential grounds for brackish water shrimp aquaculture. For this reason, Asian countries, China being the first and India, Vietnam, Indonesia, Thailand, Bangladesh and Philippine among many other countries, dominate the tropical and sub-tropical aquaculture that provides more than $90 \%$ of the world aquaculture production (Sapkota(a), Sapkota(b), Kucharski, Burke, McKenzie, Walker \& Lawrence, 2008; Rico, Satapornvanit, Haque, \& van den Brink, 2010). Simultaneously, the industry generates and discharges huge volume of polluted water at the cost of quality and sustainability of the receiving environment that may lead to many social problems.

Moreover, nutrient like phosphorus is known to be a lasting resource, and no alternative has been so far identified in place of phosphorus (Ebie, kondo, Kadoya, Mouri, Maruyama, Noritake, Inamori, \& Xu, 2008) for agricultural and other uses. Even though phosphorus in the world will be end up within next 345 years, at the rate of present consumption, a "peak phosphorus" is predicted to be occurred in 30 years, thereby end up of world phosphorus reserves has been advanced to the next 50 to 100 years (Malavipathirana, Wimalasiri, Priyantha, Wickramasooriya, Welagedara, \& Renman, (submitted)). Therefore, scarcity of nutrient such as phosphorus in the future deserves attention of scientists (Ebie, kondo, Kadoya, Mouri, Maruyama, Noritake, Inamori, \& Xu, 2008; Kawasaki, Ogata, \& Tominaga, 2010). Consequently, many innovative approaches have been in progress in different ways and means. For instance, recovery (treatment) of wastewater rich in nutrients and/or reuse of either such recovered nutrients or the adsorbent itself used for nutrient adsorption or both. The need of removal of nutrients from wastewater is, thus confirmed. Accordingly, research is in need for development of sustainable and affordable technologies for treatment of waste containing nutrients, and reuse of them as much as possible, especially in consideration of financial constrains for environmental remediation in developing countries.

This paper explains the ability of a solid waste material (crushed autoclaved aerated concrete - CAAC) that consists of $\mathrm{SiO}_{2}$ and $\mathrm{CaO}$, for repeated applications in order to remove available $\mathrm{PO}_{4}^{3-}$ - P from simulated brackish water. Thereby, this approach functions in several means by value addition to the solid waste material, management of pollution load caused by $\mathrm{PO}_{4}^{3-}$ in wastewater, and concurrently explore the viability of the adsorbent to use as a phosphorus-based fertilizer.

\section{Materials and Methods}

\section{Materials and Chemicals}

Scrap material from the production of autoclaved aerated concrete (AAC) was crushed and graded into 2 - 4 mm (CAAC), used in this study was obtained from Royal Institute of Technology, Sweden. Solutions of phosphate at different concentrations were prepared by analytical grade potassium dihydrogen orhtophosphate dried at $105^{\circ} \mathrm{C}$ until it reached a constant mass, obtained from Hopkin and Williams Ltd., England. Ammonium metavanadate (Hopkin and Williams Ltd., England), Ammonium molybdate tetrahydrate and hydrochloric acid (Fluka, UK) were used as purchased in order to prepare the Vanadate-Molybdate reagent. Sodium chloride was purchased from Loba Che- mie, India and used to simulate brackish water condition. All the standards and samples were prepared in simulated brackish water.

\section{Instrumentation}

SK 600 Lab Companion orbital shaker was used to perform contact batch experiments. The absorbance of working standards and filtered solutions was measured at $470 \mathrm{~nm}$ by means of Shimadzu UV 1800 UV/Vis spectrophotometer.

\section{Research Design}

Preparation of Working Standards: Serial dilutions of the stock phosphate standard solution were made in order to prepare working standards in the range of 1 to $16 \mathrm{mg} \cdot \mathrm{dm}^{-3} \mathrm{PO}_{4}^{3-}$ - P.

Determination of sorption capacity: The sorption capacity of the adsorbent was ascertained via batch experiments. A constant amount of the adsorbent was made into contact with a known volume of the phosphate solution of predetermined concentration. The amount of $\mathrm{P}$ sorbed to the adsorbent was expressed in unit mass of $\mathrm{P}$ per unit mass of the adsorbent. Optimized contact time of $240 \mathrm{~min}$ at $150 \mathrm{rpm}$, and the settling time of 20 min were remained constant as identified by the previous research of the same researchers (Malavipathirana, Wimalasiri, Priyantha, Wickramasooriya, Welagedara, \& Renman, (submitted)).

Isotherm Studies: Under the optimized conditions, replicate experiments were carried out at different $\mathrm{PO}_{4}^{3-}$ - $\mathrm{P}$ concentrations so that modelling of isotherm characteristics would be established.

Spectrophotometric Measurements: Phosphorus content of all samples was determined at $470 \mathrm{~nm}$ as per the vanadomolybdophosphoric acid colorimetric method.

\section{Results and Discussion}

In the way of finding a good adsorbent, optimization of adsorption characteristics is a must (Lim, Priyantha, Tennakoon, \& Dahri, 2012; Pillai, Mullassery, Fernandez, Girija, Geetha, \& Koshy, 2013). An adsorbent that takes a little time to attain its optimum performance, and if it can be repeatedly used or it can uptake higher sorbate amount, such a material can be considered as a good adsorbent. CAAC used in the study was exhibited reasonably acceptable optimum contact time of $240 \mathrm{~min}$ followed by 20 min settling time for its best performance. Thus, all subsequent experiments were carried out at these optimum conditions.

\section{Distribution Coefficient}

Distribution coefficient $\left(K_{D}\right)$ defined as the ratio between the concentration of an analyte in the solid phase (adsorbent) to that of the aqueous phase at the equilibrium, is an indication of the relative effectiveness of an adsorbent. Therefore, CAAC as an adsorbent for removal of phosphate can be expressed with respect to the distribution coefficient $\left(K_{D}\right)$ of the system. The $K_{D}$ is compelled to be a linear adsorption model with the assumption that adsorption of the sorbate of interest is essentially independent of its concentration in the aqueous phase. (Goldberg, 1995), Nevertheless, the truth behind practical situation is that adsorption of a sorbate can deviate from the linear relationship 
required by the $K_{D}$. Because, solution phase concentration of a sorbate may increase to a level high enough to occupy all adsorption sites where the linear relationship between the sorbate already adsorbed to that remains in bulk solution would no longer exist, and leading the system to satisfy non-linear adsorption. Thus, in the context of non-linear adsorption, $K_{D}$ of a system varies with the concentration of the sorbate (Grathwohl, 2005/06).

Distribution coefficients always greater than 1 , as depicted in Table 1, with respect to different initial concentrations, indicate that concentration of the analyte (phosphate) at the sorbent water interface is higher than that in the continuous aqueous phase. CAAC as an effective adsorbent towards phosphate removal from simulated brackish water is thus, established. The maximum value of $K_{D}$ (at $100 \mathrm{mg} \cdot \mathrm{dm}^{-3} \mathrm{PO}_{4}^{3-}$ - P) was accompanied by 10 fold variation with respect to its value at the initial concentration $\left(10 \mathrm{mg} \cdot \mathrm{dm}^{-3} \mathrm{PO}_{4}^{3-}-\mathrm{P}\right)$. In contrast to a small change in the values of $K_{D}$ associated with concentration that indicates non-complex interactions, the change in concentration as same order as of $K_{D}$, indicates complex interaction between the adsorbent and the adsorbate (Okieimen, Okundia, \& Ogbeifun, 1991). Recovery of adsorbed phosphate is not, thus practically simple. Nevertheless, the maximum adsorption of $98 \%$ attributed at the highest $K_{D}$ of 40 at $100 \mathrm{mg} \cdot \mathrm{dm}^{-3} \mathrm{PO}_{4}^{3-}$ - P implies that CAAC is an effective adsorbent towards phosphate removal from simulated brackish water.

\section{Isotherm Studies}

In the event that adsorption occurs deviation from linearity, isotherm models are in place to describe such non-linear adsorption. Consequently, existence of equilibrium of an adsorbate between the solution phase and the solid phase (adsorbent) can be explained in terms of an isotherm (Lichtfouse, Schwarzbauer, \& Robert, 2005). As evident by the values of $K_{D}$, nonlinear adsorption of $\mathrm{PO}_{4}^{3-}$ - P on CAAC was apparent. Therefore, the simplest and the most usually used isotherms models, the Langmuir and the Freundlich isotherm models are to be satisfied by the adsorption of $\mathrm{PO}_{4}^{3-}-\mathrm{P}$ from liquid phase onto solid phase.

Langmuir Isotherm Model: This is a simple and widely used model. The validity of the model is based on the following assumptions;

- The sorbate upon adsorption is associated within a well defined site of the adsorbent.

- The individual site of the adsorbent gets only one adsorbed species.

- The same energy of adsorption is associated with all the sites and it is independent of the occurrence of the adsorbed species on the adjacent sites.

This model explains monomolecular adsorption on the surface of an adsorbent.

Table 1.

Distribution coefficient $\left(K_{D}\right)$ for phosphate adsorption on CAAC.

\begin{tabular}{ccc}
\hline $\begin{array}{c}\text { Initial concentration } \\
\left(\mathrm{mg} \cdot \mathrm{dm}^{-3}\right)\end{array}$ & $\begin{array}{c}\text { Remaining concentration } \\
\left(\mathrm{mg} \cdot \mathrm{dm}^{-3}\right)\end{array}$ & $\begin{array}{c}\text { Distribution coefficient } \\
\left(K_{D}\right)\end{array}$ \\
\hline 10 & 2 & 4.07 \\
20 & 3 & 6.77 \\
30 & 3 & 10.50 \\
50 & 2 & 20.24 \\
100 & 2 & 40.60 \\
\hline
\end{tabular}

The empirical data can be fitted with the linearized form of the Langmuir modes as given below.

$$
\frac{1}{q_{e}}=\frac{1}{b q_{\max }} \frac{1}{C_{e q}}+\frac{1}{q_{\max }}
$$

where $q_{e}$ is the amount adsorbed (mg. $\mathrm{g}^{-1}$ ) from the bulk solution and $C_{e q}$ is the analyte concentration $\left(\mathrm{mg} \cdot \mathrm{dm}^{-3}\right.$ ) at the equilibrium. The maximum adsorption of an adsorbate per unit mass of an adsorbent is given by $q_{\max }$, and $b$ is the Langmuir constant. Accordingly, $q_{\max }$ and $b$ can be calculated by means of the intercept and the gradient of the plot of $1 / q_{e}$ against $1 / C_{e q}$.

Moreover, separation factor $\left(R_{L}\right)$ is an important parameter that indicates characteristics of the adsorption. The $R_{L}$ is a unitless constant as given below.

$$
R_{L}=\frac{1}{1+\left(1+b C_{0}\right)}
$$

where $C_{0}$ is the initial concentration and $b$ is the Langmuir constant. Depending on the value assigned to $R_{L}$, based on the Langmuir model, the adsorption can be explained as irreversible, favourable, linear and unfavourable if $R_{L}=0,0<R_{L}<1$, $R_{L}=1$ and $R_{L}>1$ respectively (Dada, Olalekan, Olatunya, \& Dada, 2012).

Results calculated based on the Langmuir model as given in Table 2 explain that the maximum phosphate removal (adsorption) capacity through monolayer coverage is $14.29 \mathrm{mg} \cdot \mathrm{g}^{-1}$ of CAAC, Further, being the separation factor in between 0 and $1\left(R_{L}=.474\right)$ confirms favourable adsorption that best explained by the Langmuir isotherm model with the regression coefficient of .996 .

Freundlich Isotherm Model: This model associates with the surface heterogeneity and the exponential distribution of active sites and their energies related to adsorption (Njoku, Oguzie, Obi, Bello, \& Ayuk, 2011). Understanding of compliance of the model is important because, the present study considered only single sorbate (phosphate) in contact with the sorbent (CAAC) (Palanisamy \& Sivakumar, 2009). In addition to the relevance of the Freundlich model with a single solute system, it is a practical depiction of the adsorption of an analyte in an aqueous medium onto the surface of an adsorbent (Arfaoui, Frini-Srasra, \& Srasra, 2008). The Freundlich equation can be expressed as;

$$
q_{e}=k_{f} C_{e}^{\frac{1}{n}}
$$

where $k_{f}$ and $n$ are empirical constants to be found, $C_{e}$ is the equilibrium concentration of an adsorbate $\left(\mathrm{mg} \cdot \mathrm{dm}^{-3}\right)$ while $q_{e}$ is the amount of an adsorbate adsorbed per gram of the adsorbent at equilibrium $\left(\mathrm{mg} \cdot \mathrm{g}^{-1}\right)$. Despite monolayer adsorption at the sites with identical energy, adsorption on multiple sites with diverse energies is demonstrated by the Freundlich model. The model, therefore, depicts real time closeness of a sorbate in a solution in contact with a sorbent (Priyantha \& Bandaranayaka, 2011). The linear form of the Freundlich equation can be expressed as follows:

Table 2.

Characteristic parameters of the Langmuir and the Freundlich models for the sorption of phosphate on CAAC.

\begin{tabular}{ccccccc}
\hline & Langmuir Model & \multicolumn{4}{c}{ Freundlich Model } \\
\hline$q_{\max }\left(\mathrm{mg} \cdot \mathrm{g}^{-1}\right)$ & $b\left(\mathrm{dm}^{3} \cdot \mathrm{mg}^{-1}\right)$ & $R_{L}$ & $R^{2}$ & $1 / n$ & $k_{f}$ & $R^{2}$ \\
14.29 & .0011 & .474 & .996 & .94 & 22.2 & .995 \\
\hline
\end{tabular}




$$
\log \left(q_{e}\right)=\frac{1}{n} \log \left(C_{e}\right) \operatorname{tog} k_{f}
$$

The value of the constant $k_{f}$ is an indication of approximate adsorption capacity of the adsorbent, and the strength of adsorption is a function of $1 / n$ (Dada, Olalekan, Olatunya \& Dada, 2012). As mentioned earlier, $n=1$ represents the partition between two phases where $k_{f}$ becomes $K_{D}$ which is independent of the concentration. If the constant $1 / n$ is $0<1 / n<1$ it indicates favorable adsorption while $1 / n$ of above 1 associates with cooperative adsorption.

The graphical representation of the Freundlich model is given in Figure 1, and the characteristic constants of the model for the system of interest are tabled in Table 2. From the data in Table 2, the value of $1 / n=.94$ approves favorable sorption of phosphate on CAAC with a regression coefficient of .995. Further, having a fair value of 22.2 for $k_{f}$ demonstrates association of significant number of active sites with the adsorbent.

The more promising feature of the adsorbent is the ability to satisfy both the Langmuir and the Freundlich adsorption models as depicted by almost similar regression coefficients. This is probably a reason of high porosity as observed from Figure 2 which allows diffusion of the phosphate molecules into innermost voids that occurs at the same time of monolayer adsorption. Thus, it provides more and more empty sites to be opened at the outer-most layer for subsequent adsorption. Therefore, CAAC exhibits remarkable characteristic as an adsorbent for phosphate removal from simulated brackish water.

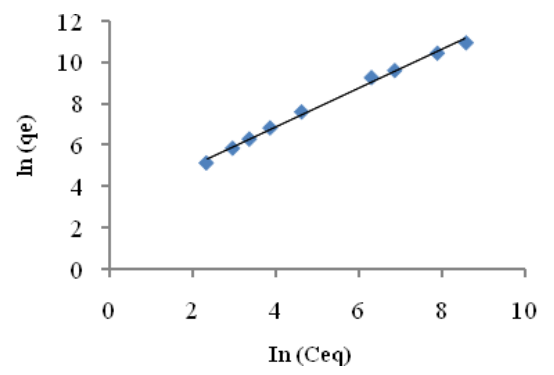

Figure 1.

Sorption of phosphate on CAAC: The Freundlich adsorption model for multilayer coverage.

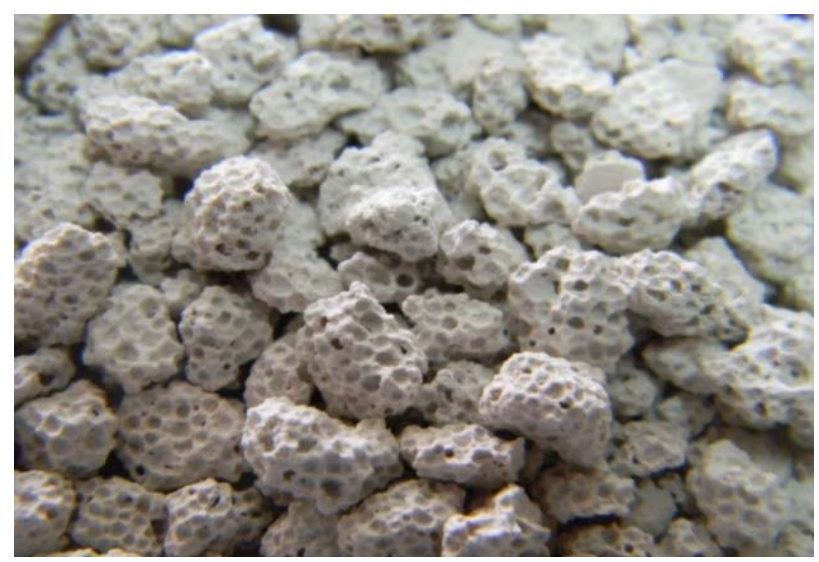

Figuer 2.

Visual image of fresh CAAC.

\section{Efficiency of Repeated Adsorption}

Repeated batch experiments were performed with the same amount of adsorbent at the concentration of the sorbate (100 $\mathrm{mg} \cdot \mathrm{dm}^{-3}$ of $\mathrm{PO}_{4}^{3-}-\mathrm{P}$ ) which gives the highest value of $K_{D}$. A fixed amount of material with mass $M(\mathrm{~kg})$ was placed in an Erlenmeyer flask containing a volume $V\left(\mathrm{dm}^{3}\right)$ of the prepared solution of phosphate. The amount of $\mathrm{P}$ adsorbed to the material (S) was expressed in unit mass of $P$ (g) per unit mass of the adsorbent (kg), and calculated as:

$$
S=\left[\left(C o-C_{e q}\right) \times V\right] / M
$$

where, $C_{0}$ and $C_{e q}$ are the initial and the equilibrium concentrations of the solution respectively. The efficacy of the adsorption is then expressed in mass of phosphate adsorbed in gram per unit mass of the adsorbent in kilogram (Renman \& Renman, 2012).

As demonstrated in Figure 3, efficacy of adsorption at the first cycle, $1.83 \pm .01 \mathrm{~g} \cdot \mathrm{kg}^{-1}$ was reduced marginally to the value of $1.63 \pm .03 \mathrm{~g} \cdot \mathrm{kg}^{-1}$ even at the end of the seventh cycle. Associated removal efficiencies are about $98 \%$ and $81 \%$ respectively (not given in Figure 3), whereas the equilibrium concentrations varied from $1.77 \pm .61 \mathrm{mg} \cdot \mathrm{dm}^{-3}$ at the first cycle to $19.49 \pm 1.45 \mathrm{mg} \cdot \mathrm{dm}^{-3}$ at the seventh cycle as illustrated in Figure 3. Even though adsorption on the surface layers of CAAC can be visually observed (Figure 4) at the end of the

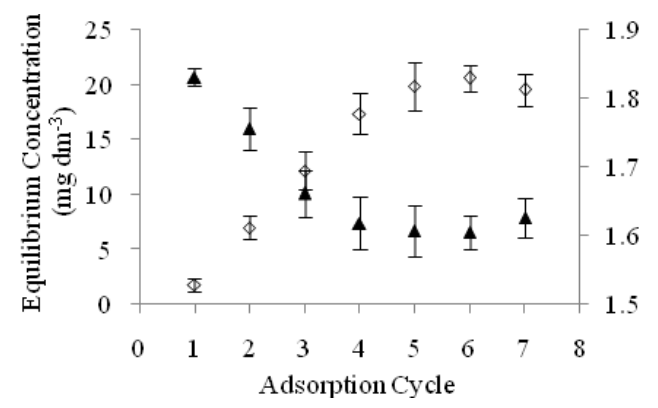

Figure 3.

Efficiency of repeated adsorption: variation of $(\diamond)$ equilibrium concentration and ) efficacy of adsorption with repeated adsorption cycle.

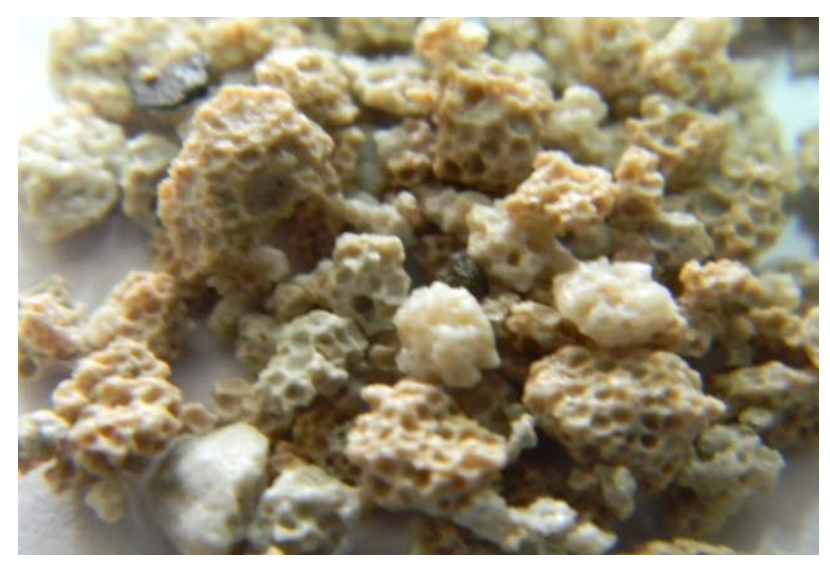

Figure 4.

Visual image of CAAC after adsorption (solution concentration 100 $\mathrm{mg} \cdot \mathrm{dm}^{-3} \mathrm{PO}_{4}^{3-}-\mathrm{P}$, Number of adsorption cycle-7). 
seventh cycle, the adsorbent is still characterized by its promising removal efficiency of $81 \%$. This means, CAAC can be considered as an excellent adsorbent in real time applications for a lengthy period as the concentration of phosphorous in real samples is generally less than $100 \mathrm{mg} \cdot \mathrm{dm}^{-3}$.

Moreover, cumulative phosphorus uptake during which cycle was estimated with the intention of use the adsorbent as a base of phosphorus fertilizer. Validity of such an understanding deserves, as substitution for phosphorus is so far unknown. As shown in Table 3 ca $12 \mathrm{~g}$ of phosphorus has been accumulated to $1 \mathrm{~kg}$ of CAAC at the removal efficiency of $81 \%$. This indicates potential of the adsorbent for further uptake of phosphorus from the solution in contact. Thus, such partially exhausted adsorbent in a separate unit can be placed in series at the beginning of the waste (phosphate rich) inflow until the unit accomplished saturation.

Nevertheless, screening experiments carried out to understand recovery/leaching ability of the adsorbent showed poor performance. Consequently, further research is in need in this aspect and the exhausted (saturated) adsorbent, at the moment, can be considered as a slow-released phosphorus fertilizer such as rock phosphate.

\section{Conclusion}

The present research proposed the use of formulated waste material, CAAC, as a potential adsorbent for removal of $\mathrm{PO}_{4}^{3-}$ - P from simulated brackish water. Under the optimized conditions, change in distribution coefficient suggests non-linear adsorption which records the highest adsorption at the value of 40. Isotherm studies supported by non-linear adsorption attributed that the adsorption of $\mathrm{PO}_{4}^{3-}-\mathrm{P}$ on CAAC behaved in compliance to both the Langmuir and the Freundlich models being the respective regression coefficients identical $\left(\mathrm{R}^{2}=.99\right)$. The adsorbent kept the adsorption ability remained at a significant level even after the seventh repeated cycle of adsorption at $100 \mathrm{mg} \cdot \mathrm{dm}^{-3} \mathrm{PO}_{4}^{3-}$ - $\mathrm{P}$ which acquired about $12 \mathrm{~g}$ of phosphorus per unit weigh of the adsorbent. This suggests that CAAC as a viable phosphate fertilizer at the end of its service life as an adsorbent.

\section{Acknowledgements}

Authors acknowledge National Science Foundation, Sri Lanka for the financial support for the research.

Table 3.

Cumulative adsorption of phosphorus on CAAC.

\begin{tabular}{ccc}
\hline Adsorption cycle & $\begin{array}{c}\text { Adsorbed amount } \\
(\mathrm{g} / \mathrm{kg})\end{array}$ & $\begin{array}{c}\text { Cumulative adsorption } \\
(\mathrm{g} / \mathrm{kg})\end{array}$ \\
\hline 1 & $1.830 \pm .012$ & 1.830 \\
2 & $1.755 \pm .031$ & 3.585 \\
3 & $1.661 \pm .034$ & 5.247 \\
4 & $1.618 \pm .038$ & 6.865 \\
5 & $1.607 \pm .037$ & 8.472 \\
6 & $1.604 \pm .024$ & 10.076 \\
7 & $1.626 \pm .029$ & 11.702 \\
\hline
\end{tabular}

\section{REFERENCES}

Arfaoui, S., Frini-Srasra, N., \& Srasra, E. (2008). Modelling of the adsorption of the chromium ion by modified clays. Desalination, 222, 474-481. http://dx.doi.org/10.1016/j.desal.2007.03.014

Colt, J. (2006). Water quality requirements for reuse systems. Aquacultural Engineering, 34, 143-156. http://dx.doi.org/10.1016/j.aquaeng.2005.08.011

Dada, A. O., Olalekan, A. P., Olatunya, A. M., \& Dada, O. (2012). Langumuir, Freundlich, Temkin and Dubinin-Radushkevich isotherms studies of equilibrium sorption of $\mathrm{Zn}^{2+}$ unto phosphoric acid modified rice husk. IOSR Journal of Applied Chemistry, 3, 38-45. http://dx.doi.org/10.9790/5736-0313845

Ebie, Y., Kondo, T., Kadoya, N., Mouri, M., Maruyama, O., Noritake, S., Inamorai, Y., \& Xu, K. (2008). Recovery oriented phosphorus adsorption process in decentralized advanced Johkasou. Water Science \& Technology-WST, 57, 1977-1981. http://dx.doi.org/10.2166/wst.2008.337

Editorial (2013). Dicyandiamide contamination of milk powders. Sri Lanka Journal of Child Health, 42, 63-64.

Goldberg, S. (1995). Ch. 5: Adsorption models incorporated into chemical equilibrium models. In Chemical Equilibrium and Reaction models (pp. 75-95). Soil Science Society of America, American Society of Agronomy.

Grathwohl (2005/06). Sorption III: Models, HGC 1 2005/06 (pp. sorption 1-15).

Kawasaki, N., Ogata, F., \& Tominaga, H. (2010). Selective adsorption behavior of phosphate onto aluminum hydroxide gel. Journal of Hazardous Materials, 181, 574-579. http://dx.doi.org/10.1016/j.jhazmat.2010.05.051

Kuzawa, K., Jung, Y.-J., Kiso, Y., Yamada, T., Nagi, M., \& Lee, T.-G. (2006). Phosphate removal and recovery with a synthetic hydrotalcite as an adsorbent. Chemosphere, 62, 45-52. http://dx.doi.org/10.1016/j.chemosphere.2005.04.015

Le, T. X., \& Munekage, Y. (2004). Residues of selected antibiotics in water and mud from shrimp ponds in mangrove areas in Viet Nam. Marine Pollution Bulletin, 49, 922-929.

http://dx.doi.org/10.1016/j.marpolbul.2004.06.016

Lichtfouse, E., Schwarzbauer, J., \& Robert, D. (2005). Environmental chemistry, green chemistry and pollutants in ecosystem. New York: Springer International Ed.

Lim, L. B. L., Priyantha, N., Tennakoon, D. T. B., \& Dahri, M. K. (2012). Biosorption of cadmium(II) and copper(II) ions from aqueous solution by core of Artocarpus odoratissimus. Environmental Science and Pollution Research, 19, 3250-3256. http://dx.doi.org/10.1007/s11356-012-0831-2

Malavipathirana, S., Mubarak, M. N. A., \& Perera, K. M. P. A. H. (2013). An assessment of heavy metal contamination in marine sediments: Precautionary measures for environmental impact management at harbor development-Galle harbor Sri Lanka. Journal of Ecotechnology Research, 17, 29-33.

Malavipathirana, S., Wimalasiri, S., Priyantha, N., Wickramasooriya, S., Welagedara, A., \& Renman, G. (2013). removal of available phosphate from simulated brackish water-A low cost preliminary approach. International Journal of Earth Science and Engineering (submitted).

Marhaba, T. F., Mangmeechai, A., Chaiwatpongsakorn, C., \& Pavasant, P. (2006). Trihalomethane formation potential of shrimp farm effluents. Journal of Hazardous Materials, 136, 151-163. http://dx.doi.org/10.1016/j.jhazmat.2005.12.011

Njoku, V. O., Oguzie, E. E., Obi, C., Bello, O. S., \& Ayuk, A. A. (2011). Adsorption of copper(II) and lead(II) from aqueous solutions onto a Nigerian natural clay. Australian journal of Basic and Applied Sciences, 5, 346-353.

Okieien, F. E., Okundia, E. U., \& Ogbeifun, D. E. (1991). Sorption of cadmium and lead ions on modified groundnut (Arachis hypogea) husks. Journal of Chemical Technology and Biotechnology, 51, 97103. http://dx.doi.org/10.1002/jctb.280510110

Paul, B. G., \& Vogal, C. R. (2011). Impacts of shrimp farming in Bangladesh: Challenges and alternatives. Ocean and Coastal Management, 54, 201-211. 


\section{S. MALAVIPATHIRANA ET AL.}

http://dx.doi.org/10.1016/j.ocecoaman.2010.12.001

Palanisamy, P. N., \& Sivakumar, P. (2009). Kinetic and isotherm studies of the adsorption of Acid Blue 92 using a low-cost non-conventional activated carbon. Desalination, 249, 388-397. http://dx.doi.org/10.1016/j.desal.2009.09.006

Pillai, S. S., Mullassery, M. D., Fernandez, N. B., Girija, N., Geetha, P., \& Koshy, M. (2013). Biosorption of Cr(VI) from aqueous solution by chemically modified potato starch: Equilibrium and kinetic studies. Ecotoxicology and Environmental Safety, 92, 199-205. http://dx.doi.org/10.1016/j.ecoenv.2013.01.020

Priyantha, N., \& Bandaranayaka, A. (2011). Interaction of Cr(VI) species with thermally treated brick clay. Environmental Science and Pollution Research, 18, 75-81.

http://dx.doi.org/10.1007/s11356-010-0358-3

Renman, G., \& Renman, A. (2012). WASCON 2012 Conference proceedings. Sustainable use of crushed autoclaved concrete (CAAC) as a filter medium in wastewater purification.

Rico, A., Satapornvanit, K., Haque, M. M., \& van den Brink, P. (2010). Contamination risks: Situation appraisal, Use of chemicals and bio- logical products in (sub)tropical Asian Aquaculture: current situation and research needs for an environmental risk assessment. SEAT Deliverable Ref: D 2.5b. University of Stirling, Institute of Aquaculture, United Kingdom, University of Copenhagen, Faculty of Life Sciences, Denmark, Shanghai Ocean University College of Fisheries and life Sciences, China, can Tho University College of Aquaculture and Fisheries, Vietnam and The Food and Agriculture organization, Italy.

Sapkota, A., Sapkota, A. R., Kucharski, M., Burke, J., McKenzie, S., Walker, P., \& Lawrence, R. (2008). Aquaculture practices and potential human health risks: Current knowledge and future priorities. Environmental International, 34, 1215-1226.

http://dx.doi.org/10.1016/j.envint.2008.04.009

Wu, X.-Y., \& Yang, Y.-F. (2010). Accumulation of heavy metals and total phosphorus in intensive aquatic farm sediments: Comparison of tilapia Oreochromis niloticus $\times$ oreochromis aureu, Asian seabass Lates calcarifer and white shrimp Litopenaeus vannamei farms. Aquaculture Research, 41, 1377-1386.

http://dx.doi.org/10.1111/j.1365-2109.2009.02427.x 